\title{
Factors Influencing Overweight Among Teachers in South-South Nigerian Training College and Development of a Self Assessment Checklist for Overweight
}

\author{
Emmanuel Amaechi Ojeogwu*, Tengku Mohammad Afiff Bin Raja Husin
}

Faculty of Medicine, Universitit Sultan Zainal abidin, Terengganu, Malaysia

DOI: $10.36347 /$ simcr.2020.v08i01.027

| Received: 16.01.2020 | Accepted: 23.01.2020 | Published: 29.01.2020

*Corresponding author: Emmanuel Amaechi Ojeogwu

Abstract

Original Research Article

Teachers constitute an important fraction of Nigerian workforce whose sedentary nature of work lead them to intake of calorie dense food and more sitting during the day. Overweight and obesity seem to be responsible for the occurrence of diseases among the workers. The study therefore determined the factors influencing overweight among teachers in Nigeria. 360 teachers ranging from head teachers, classroom teachers and school heads were recruited for this study. Demographic and socioeconomic data were collected using a structured questionnaire. 165 (46\%) were male while $195(54 \%)$ were female with average age of $40.9 \pm 8.8$ years and average body mass index (BMI) of $26.7 \pm 5.9 \mathrm{~kg} / \mathrm{m}^{2}$. BMI and blood pressure measurements were taken using standard techniques. BMI was classified using the National Institutes of Health criteria, 2000. Pearson's product moment correlation coefficient at 0.05 level of significance was used to test the relationship between variables. Based on BMI, the prevalence of overweight and generalized obesity among teachers in South South Nigeria Training Colleges, were $31.7 \%$ and $25.5 \%$, respectively. Overweight and obesity are more common among female teachers than their male counterparts. Using the waist circumference, approximately $60 \%$ of the teachers had central obesity, while $57.2 \%$ are either overweight or obese. The high prevalence of overweight and obesity seen among teachers calls for the introduction of therapeutic lifestyle modification in this group of workers which can be achieved through appropriate health education and interventional measures.

Keywords: Obesity, overweight, therapeutic lifestyle modification.

Copyright @ 2020: This is an open-access article distributed under the terms of the Creative Commons Attribution license which permits unrestricted use, distribution, and reproduction in any medium for non-commercial use (NonCommercial, or CC-BY-NC) provided the original author and source are credited.

\section{INTRODUCTION}

Obesity and Overweight has really risen with a high negative health status on children, adult and old; together with related diseases like type 2 diabetes, hypertension, cardiovascular diseases, such as asthma and so on; obesity has become as epidemic as the case of HIV virus and a gate way for all illnesses.

According to WHO report in 2016, more than 1.9 billion adults aged 18 years and older were overweight. Of these over 650 million adults were obese, and in 2016, 39\% of adults aged 18 years and over (39\% of men and $40 \%$ of women) were overweight. Total estimation is about $13 \%$ of the world's adult population (11\% of men and $15 \%$ of women) were obese in 2016. Which says that the worldwide prevalence of obesity nearly tripled between 1975 and 2016.which in 2016, an estimated 41 million children under the age of 5 years were overweight or obese. Once considered a high-income country problem, overweight and obesity are now on the rise in low- and middle-income countries, particularly in urban settings. In Africa, the number of overweight children under 5 has increased by nearly 50 per cent since 2000 . Nearly half of the children under 5 who were overweight or obese in 2016 lived in Asia. Over 340 million children and adolescents aged 5-19 were overweight or obese in 2016. The prevalence of overweight and obesity among children and adolescents aged 5-19 has risen dramatically from just 4\% in 1975 to just over $18 \%$ in 2016 . The rise has occurred similarly among both boys and girls: in $201618 \%$ of girls and $19 \%$ of boys were overweight. While just under $1 \%$ of children and adolescents aged 5-19 were obese in 1975, more 124 million children and adolescents ( $6 \%$ of girls and $8 \%$ of boys) were obese in 2016 [1]. 
Overweight and obesity are linked to more deaths worldwide than underweight. Globally there are more people who are obese than underweight - this occurs in every region except parts of sub-Saharan Africa and Asia. People are generally considered obese when their body mass index (BMI) is over $30 \mathrm{~kg} / \mathrm{m}^{2}$. Body mass index, BMI is a measurement obtained by dividing a person's weight by the square of the person's height. Its normal value should always be lower than 25. The BMI range of $25-30 \mathrm{~kg} / \mathrm{m} 2$ is defined as overweight [1].

One of the earliest measures that was taken to address obesity and overweight was nutritional labelling, which is required on packaged food sold in markets, which provide list of calories, such information considered useful for the consumers looking monitor their weight and be informed of nutritional values their purchases. Also, in the United States, a law requiring nutritional labelling was passed in 1990. Canada passed its own nutritional labelling law in 2003 and Mexico has had one since 1996. Many other countries in the world have some forms of nutritional labelling. Other countries are also considering a menu labelling law, particularly for fast food outlets.

Obesity and overweight if seen as a disease on itself is epidemic or in fact pandemic. It not only causes the overweight individuals to feel low in selfconfidence, but it is a gateway to multitude of other diseases. These call for the need to carryout a study that will statistically establish factors responsible for increase rate of overweight and obesity among teachers Nigeria. Teachers constitute an important fraction of Nigerian workforce that plays significant role in the educational sector; these set of worker are described as sedentary workers due to the nature of their work which allows for more sitting during the day [2]. Only few nutrition studies in Nigeria have focused on adults particularly teachers to crown it almost all school based nutrition studies and interventions in Nigeria are focused on school children, their health and academic performance [3]. This work is therefore designed to evaluate the prevalence of overweight and obesity among teachers and to determine the factors influencing overweight and obesity among teachers in South South Nigeria colleges.

To aid this assessment towards a clear healthy living with measures of addressing overweight and obesity ranging each factors related to diet, physical activity to weight management and attitudinal change, using multi component maintenance programs.

\section{Factors and Causes of Overweight and Obesity}

There are so many factors causing obesity; it maybe impact factors or influence factors. According to Galletta and Balentine [4], there are causes and reasons for the imbalance between calorie intake and consumption. It varies by individual. Your age, gender, genes, psychological makeup, socioeconomic, and environmental factors all may contribute.

Children can become overweight or obese due to many reasons. The most common causes are lack of physical activity, unhealthy eating patterns, or a combination of these factors. It is possible that being overweight can be caused by a medical condition such as a hormonal problem. However, such cases are usually rare. A physical examination and some blood tests by the doctor can usually rule out medical causes of obesity.

\section{Genes}

Your genes may play a role in efficiency of metabolism and storage and distribution of body fat and some people have concluded with that fact by not trying to lose weight because it runs in the family blood.

It may be true that certain genetic traits inherited from your parents - such as having a large appetite - may make losing weight more difficult, but it certainly doesn't make it impossible. In many cases, obesity is more to do with environmental factors, such as poor eating habits learned during childhood.

\section{Family lifestyle}

Obesity tends to run in families. This is caused both by genes and by shared diet and lifestyle habits. If one of your parents is obese, you have a higher risk of being obese as a result of illusion in action.

\section{Emotions}

Some people overeat because of depression, hopelessness, anger, boredom, and many other reasons that have nothing to do with hunger. It does not mean that overweight and obese people have more emotional problems over others. It just means that their feelings influence their eating habits thereby causing binge eating.

\section{Environmental factors}

The most important environmental factor is lifestyle. Eating habits and activity level are primarily learnt from the people around you. Overeating and sedentary habits (inactivity) are the most important risk factors for obesity which has really impacted more populations to epidemic proportions.

\section{Socioeconomic factors}

Do you live in a neighbourhood where it is safe to exercise outdoors? Is there a supermarket with fresh foods in your neighbourhood? Answers to this question determine a community's obesity level.

\section{Sex (Gender)}

Men have more muscles than women, on average. Because muscle burns more calories than other types of tissue, men use more calories than women, 
even at rest. Thus, women are more likely than men to gain weight with the same calorie intake. Age People tend to lose muscle and gain fat as they age. Aging too, has its factor on obesity. A slower metabolism due to a lower age leads to lower calorie requirements and consequently higher weight gain.

\section{Pregnancy}

Women tend to weigh an average of 4-6 pounds more after a pregnancy than they did before the pregnancy. This can compound with each pregnancy. Certain medical conditions and medications can cause or promote obesity, although these are much less common causes of obesity than overeating and inactivity. Some examples of these are as follows:

1. $\square$ †Cushing syndrome

2. $\square$ †Depression

3. $\square$ †ertain medications (examples are steroids, antidepressants, birth control pills)

4. $\square \uparrow$ Prader-Willi syndrome

5. $\square$ †Polycystic ovarian syndrome.

6.

\section{Knowledge, Attitude and Practice of Overweight among Teachers}

Descriptive studies on nutrition-related knowledge of teachers demonstrated that these teachers possess only a limited amount of nutrition-related knowledge. Lanier, et al. [5] examined factors associated with elementary school teacher awareness and implementation of their schools' food and physical activity policies and discovered that of 1,243 teacher respondents, $546(44 \%)$ were aware of the food policy and $550(44 \%)$ were aware of the physical activity policy. Hongyan, et al. [6] examined the nutritionrelated knowledge, attitudes, and practices (KAP) of kindergarten teachers in Chongqing, China and found that Multiple regression analysis confirmed significant independent effects on the nutrition knowledge score (p $<0.0001$ ) of respondents on age, type of residence, type of kindergarten, body mass index (BMI), professional training of kindergarten teachers, behaviour of having ever participated in childhood nutrition education knowledge courses or training, and behavior of having ever paid attention to children's nutrition knowledge. Indicating that necessary training measures need to be carried out to improve the nutrition-related knowledge level among kindergarten teachers in China. Okudu et al. [2] in their study on lifestyle and prevalence of overweight and obesity among secondary school teachers revealed that prevalence of overweight and obesity grade 1 was more in the female teachers (36.1 and $7.2 \%$ ). Adding that waist-hip ratio classification (WHR) showed majority of the male teachers (91.5\%) were at low risk of having cardiovascular diseases, while majority of the female teachers $(75.9 \%)$ were at high risk of cardiovascular diseases. Indicating therefore supporting that there was significant relationship between socioeconomic status with physical exercise, time spent on exercise and meals skipped.

Prevalence of obesity and overweight is high, being higher in the urban population. Hence obesity and overweight are more prevalent among females and middle-aged persons in both settings. The odds of having high BMI $(\geq 25 \mathrm{~kg} / \mathrm{m} 2)$ are highest among urban dwellers with a lower level of education [7].

\section{Material AND Methods}

The purpose of this study is to examine prevalence of overweight and its causative factors among teachers in training colleges in South South Nigeria. This section describes the systematic methods of implementing its accomplishment which include discussion on its collection choosing quantitative method of phenomenological research, inquiry using international cut-off point strategy on humans to conduct this research. Additionally, this chapter explains the participant-selection, data collection, data analysis procedure and trustworthiness of this study. Ethical approval for this study was obtained from the Teachers in south-south Nigerian colleges.

The cross-sectional descriptive study of all consenting teachers of the colleges was carried out between September and December, 2019. The quantitative approach or design was employed to address the objective of this study. The sample size was determined using the formula by Daniel [6] for descriptive studies. $\mathrm{N}=\mathrm{Z}^{2} \mathrm{PO} / \mathrm{d}^{2}$ Where $\mathrm{N}=$ Minimum sample size $Z=$ Standard deviation scores at $95 \%=$ $1.96 \mathrm{P}=$ Prevalence of obesity and overweight based on body mass index (BMI) of teachers in South South Nigeria reported at $72 \%=0.72 \mathrm{Q}=$ Complimentary probability $(1-\mathrm{P})=1-0.72=0.28 \mathrm{~d}=$ Erro margin $=$ $5 \%$ substituting, $\mathrm{N}=(1.96)^{2} * 0.72 \times 0.28 /(0.05)^{2}=$ 361.7

This sample size was rounded up to 360 to cover for $10 \%$ nonresponse. The target population was given a participant's information sheet and a consent form. All consenting staff was then given a questionnaire assessing sociodemographic data, followed by physical examination to take weight, height, and waist circumference (WC). Weight and height were recorded using a weight beam/stadiometer (Detecto, US) in line with the WHO protocols. WC was also measured in line with the WHO protocol using a nonstretch tape measure (Butterfly, China).

The data was analysed using descriptive and inferential statistics. Results were reported as proportions and means while relationships were tested using Pearson's product moment correlation coefficient at 0.05 level of significance. 


\section{RESULTS}

Table-1: Analysis of the relationship between demographic variables and knowledge of overweight among teachers in South South Nigeria colleges

\begin{tabular}{|c|c|c|c|c|c|}
\hline \multirow{2}{*}{\multicolumn{2}{|c|}{$\begin{array}{l}\text { Variables } \\
\text { Knowledge of Overweight }\end{array}$}} & $\mathbf{N}$ & $\mathbf{r}$ & $\mathbf{P}$ & Remark \\
\hline & & \multirow{5}{*}{360} & & & \multirow[t]{5}{*}{ 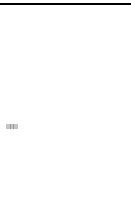 } \\
\hline \multirow{4}{*}{ Demography } & Gender & & -0.28 & 0.50 & \\
\hline & Religion & & -0.01 & 0.75 & \\
\hline & Marital Status & & 0.07 & 0.17 & \\
\hline & Level of Education & & 0.02 & 0.61 & \\
\hline
\end{tabular}

Table 1 shows a Pearson's correlation analysis which was conducted to determine the nature of the relationship that exists between demographic variables and knowledge of overweight among teachers in South South Nigeria colleges. The result shows that $\mathrm{r}=-0.28$, $\mathrm{p}>0.05 ; \mathrm{r}=-0.01, \mathrm{p}>0.05 ; \mathrm{r}=0.07, \mathrm{p}>0.05 ;$ and $\mathrm{r}=-$
$0.02, \mathrm{p}>0.05$ level of significance for gender, religion, marital status and level of education respectively. This therefore implies that no significance relationship exists between demographic variables and knowledge of overweight among teachers in South South Nigeria colleges.

Table-2: Analysis of the relationship between demographic variables and attitude towards overweight among teachers in South South Nigeria colleges

\begin{tabular}{|c|c|c|c|c|c|}
\hline \multicolumn{2}{|l|}{ Variables } & $\mathbf{N}$ & $\mathbf{r}$ & $\mathbf{P}$ & Remark \\
\hline \multicolumn{2}{|c|}{ Attitude towards Overweight } & \multirow{5}{*}{360} & & & \multirow{5}{*}{ 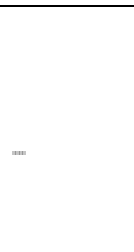 } \\
\hline \multirow{4}{*}{ Demography } & Gender & & -0.16 & 0.02 & \\
\hline & Religion & & 0.02 & 0.06 & \\
\hline & Marital Status & & 0.03 & 0.09 & \\
\hline & Level of Education & & -0.03 & 0.04 & \\
\hline
\end{tabular}

$\alpha=0.05$ Not Significant

In Table 2, A Pearson's correlation analysis was conducted to ascertain the relationship that exists between demographic variables and attitude towards overweight among teachers in South South Nigeria colleges. The result shows that for gender, $r=-0.16$, $\mathrm{p}>0.02$; for religion, $\mathrm{r}=-0.02, \mathrm{p}>0.06$; for marital status, $r=0.03, p>0.09$; and for level of education, $r=$ 0.03 , $p>0.04$ level of significance. This therefore implies that there is no significance relationship between demographic variables and attitude towards overweight among teachers in South South Nigeria colleges.

Table-3: Analysis of the relationship between demographic variables and practices towards prevention of overweight among teachers in South South Nigeria colleges

\begin{tabular}{|c|c|c|c|c|c|}
\hline \multicolumn{2}{|l|}{ Variables } & $\mathbf{N}$ & $\mathbf{r}$ & $\mathbf{P}$ & Remark \\
\hline \multicolumn{2}{|c|}{ Practices towards Prevention of Overweight } & \multirow{5}{*}{360} & & & \multirow{4}{*}{ Not Significant } \\
\hline \multirow{4}{*}{ Demography } & Gender & & 0.09 & 0.08 & \\
\hline & Religion & & 0.02 & 0.15 & \\
\hline & Marital Status & & -0.02 & 0.09 & \\
\hline & Level of Education & & -0.17 & 0.001 & Significant \\
\hline
\end{tabular}

Table 3 shows the result of a Pearson's correlation analysis which was carried out to determine the relationship that exists between demographic variables and practices towards prevention of overweight among teachers in South South Nigeria colleges. The result shows that for gender, $r=0.09$, $\mathrm{p}<0.08$; for religion, $\mathrm{r}=-0.02, \mathrm{p}>0.05$; for marital status, $r=-0.02, p>0.05$; and for level of education, $r=$ $-0.05, p>0.05$ level of significance. This therefore implies that level of education has a significant relationship with practices towards prevention of overweight among teachers in South South Nigeria colleges while religion, marital status and gender has no significant relationship with practices towards prevention of overweight among teachers in South South Nigeria colleges.

\section{DiscUSSIONS}

From the results obtained, it clearly shows that teachers in South South Nigeria colleges have a high knowledge of overweight. This was supported further by the acceptance of the null hypotheses, which implies that no significance relationship exists between 
demographic variables and knowledge of overweight among teachers in South South Nigeria colleges. This is also corroborated by Adediran, Adebayo and Akintunde [8] whose study revealed that the odds of having a high BMI $\geq 25 \mathrm{~kg} / \mathrm{m}^{2}$ were highest among urban dwellers with the lower level of education compared with rural dwellers which may be due to acquired knowledge and awareness of the risk of unhealthy lifestyle choices.

Secondly, the result further showed that teachers in South South Nigeria have a high attitude towards overweight as the null hypothesis was accepted indicating that there is no significance relationship between demographic variables and attitude towards overweight among teachers in South South Nigeria. This is in agreement with the findings of Luck-Sikorski et al. [9].

Whose study revealed that media and public health campaigns may solidify beliefs that obesity is due to individual causes and consequently increase stigma when presenting individual behavior as a cause of obesity adding that public health messages that emphasize the role of social environmental or genetic causes may be ineffective because of entrenched beliefs.

Thirdly, the result also showed that teachers in South South Nigeria practice prevention of overweight as the hypotheses test revealed that level of education has a significant relationship with practices towards prevention of overweight among teachers in South South Nigeria while religion, marital status and gender has no significant relationship with practices towards prevention of overweight among teachers in South South Nigeria. This is supported by the result of the study conducted by Cutler and Lleras- Muney [10] who found that those with more years of schooling are less likely to smoke, drink a lot, to be overweight, or obese. This is also corroborated by Ogden, Carroll, Kit and Flegal $[11,12]$ who found that obesity prevalence increases as attained educational status decreases more especially among women. The desire to lose weight is higher among the educated than the less educated obese; hence, the possible high prevalence of obesity among those of the low socioeconomic status.

\section{Conclusion}

The prevalence rate of obesity will be high among the teachers if practices toward the fight of overweight is neglected, thereby indicating an urgent need for health and nutrition education programs that focuses on various aspects of leading a healthy life. These activities could be incorporated in schools and schools can be used as a place for promoting health education in such a way that it helps to drastically reduce the risk of chronic diseases and introducing time management skills which is a time saving ingredients to life co-morbidities in our population.

\section{REFERENCES}

1. WHO (2018). Fact sheet - Obesity and overweight. Updated February 2018. Online, https://www.who.int/en/news-room/factsheets/detail/obesity-and-overweight

2. Okudu HO, Okolie VU and Chijioke MC. Lifestyle and Prevalence of Overweight and Obesity among Secondary School Teachers in Uzo-Umahi LGA of Enugu State, Nigeria. Food Sci Nutr Technol.2018; 3(5): 000161.

3. Sabir AA, Balarabe S, Sanni AA, Isezuo IA, Bello KS and Jimoh AO. Prevalence of diabetes mellitus and its risk factors among suburban population of North-Mestern Nigeria. Sahel Med J.2017; 20:16872.

4. Galletta GM and Balentine JR. Obesity. Emedicinehealth. 2016 https://www.emedicinehealth.com/obesity/article_e m.htm\#obesity_facts

5. Lanier P, Jonson-Reid M, Stahlschmidt MJ, Drake B, Constantino J. Child maltreatment and pediatric health outcomes: a longitudinal study of lowincome children. J Pediatr Psychol. 2010; https://doi.org/10.1093/jpepsy/jsp086.

6. Hongyan Zhao, Ning Zhao, Peng Zheng, Xiaohong Xu, Meijie Liu, Dan Luo, ihui Xu and Dahong J. Prevention and Treatment of Osteoporosis Using Chinese Medicinal Plants: Special Emphasis on Mechanisms of Immune Modulation. Hindawi Journal of Immunology Research. 2018; 10:55, 111. https://doi.org/10.1155/2018/6345857.

7. Umuerri EM, Ayandele $\mathrm{CO}$ and Eze G.U. Prevalence and sociodemographic correlates of obesity and overweight in a rural and urban community of Delta State, Nigeria. Sahel Med J. 2017; 20:173-8

8. Adediran OS, Adebayo PB \& Akintunde AB. Anthropometric differences among natives of Abuja living in urban and rural communities: correlations with other cardiovascular risk factors. BMC Research Notes. 2013; 6:123.

9. Luck-Sikorski C, Riedel-Heller SG and Phelan JC. Changing attitudes towards obesity - results from a survey experiment. BMC Public Health.2017; $17: 373,2-13$

10. Cutler DM and Lleras-Muney A. Education and Health: Evaluating Theories and Evidence. NBER Working Paper No. 2006; 12352, JEL No. 11, I2.

11. Ogden CL, Carroll MD and Flegal KM. "High Body Mass Index for Age among US Children and Adolescents, 2003-2006." JAMA.2013; 299.20: 2401-2405.

12. Dankyau M, Shu'aibu JA, Oyebanji AE and Mamven OV. Prevalence and correlates of obesity and overweight in healthcare workers at a tertiary hospital. J Med.2016; Trop. 18:55-59. 